orer the rights of Convocation as distinguished from outside bodies. Surely he cannot give a tacit assent to this scheme. Anyway, a committee of Convocation is organising opposition to the scheme, and either the honorary secretaries or myself will be glad to hear from any medical graduate who will join this commintee.

I am, Sirs, yours faithfully,

W. J. Collins, M.S., M.D , B.Sc.

1. Albert-terrace, Regent's Park, March 1st, 1801.

P.S.-Since writing the above I have received from the University a "memorandum in explanation of the scheme for the reorganisation of the University," which, unlike the scheme itself, is not "confidential." This piece justicative is presumably intended to anticipate objections on the part of Convocation. As, in dealing with the medical degrees, it states that the Royal Colleges and medical schools are solicitous of maintaining the standard and scientific character of these degrees, one can only conclude that the author of the document is a guileless innocent or a lawyer expert in compromise and totally ignorant of "the medical grievance."

\section{TREATMENT OF CHRONIC INFLAMMATORY DISEASE OF THE UTERINE APPENDAGES.}

\section{To the Editors of THE LANCET.}

SIRS,-The statements made by Dr. Herman and others on the one hand, and Dr. Cullingworth, Dr. Bantock, and myself and others to the contrary, are so widely discrapant that it will be the wisest plan for all concerned, particularly for the sake of suffering women, that some inquiry be made as to what is the cause of the misunderstanding. By strict logical analysis of the statements, it becomes perfectly evident that one factor has not been properly estimatedthat is, what may be called the personal equation. The one statement is to the effect that chronic inflammatory diseases of the uterine appendages in the majority of instances get well, and without any kind of surgical treatment. The statement, on the other hand, is that they rarely do get well, and my own conviction is that the exception is so remarkable that it may almost be discounted entirely. Trom these diverse statements of the case it must be perfectly evident that we are not speaking of the same thing, and that what Dr. Herman calls chronic inflammation of the uterine appendages, I certainly should not dignify by that term. Those of us engaged in the surgical treatment of these cases verify our diagnosis and justify our treatment of these cases by the display of the preparations, and these preparations indicate conditions of the disease which put the matter of diagnosis, at any rate, altogether beyond the question, whatever may be thought concerning the treatment. It is not so with Dr. Herman and his school, for they have so far presented no confirmation whatever of their assertions. The personal equation element then of the difficulty is that Dr. Herman does not diagnose as cases of chronic inflammatory disease of the aterine appendages those cases which we do; whereas we, on the contrary, disregard as altogether too trifling the class of cases which Dr. Herman considers to be deserving of that name. Such is my own explanation.

Personally, I see a very large number of cases which belong to the same group entirely as those of which I believe Dr. Herman is speaking, and they uniformly get well; but I never speak of these cases as coming within the category of chronic inflammatory disease of the uterine appendages. It rests with Dr. Herman to let us see some of the cases, as he understands them, in their initial stage, so that we may discover if possible where the misunderstanding lies. In fact, I do not think it would be at all a difficult matter to place a real value upon this personal equation. An experiment of a somewhat rough, but quite satisfactory, kind would settle the point. Let the two diverse schools of opinions be represented by two such persons as Dr. Herman and myself. Let Dr. Herman or anyone else of his school select a number of cases, say, twelve or twenty, or even a hundred, of what they call "chronic inflammatory disease of the uterine appendages." Let them be examined by the other representative person, say, by myself, and concerning each case on a particularda te written opinions giving diagnosis and prognosis by Dr. Herman and myself shall be placed together in a sealed envelope, neither knowing what the other has written. This envelope shall be placed in the custody of a third person to be selected by the two. After an interval of six months or twelve months, or any time which may be agreed upon in any particular case, a second examination of the patient is to be made and similar written opinions concerning the diagnosis and prognosis shall be made by each of the observers, unknown in every instance to the other. An analysis shall then be made by the third person of each group of cases, and these shall be con. trasted by the results to be ascertained by the person in whose custody the envelopes have been placed. The cases would always fall inevitably into two groups: those that had got well and those that had not, and the value of the personal equation will be determined, by one factor alone, upon which side the prognosis of recovery or the prognosis of non-recovery falls with the greater certainty. So far as my opinion goes, the treatment of either case is a matter of relative indifference so long as rest in bed during the menstrual period is made obligatory.

A personal equation of another kind seems inevitably to step in the moment the operation of removal of the uterine appendages comes to be discussed, and that has been very well illustrated in the case of Dr. William Duncan, whose critics have desired to show that he has had an improper because disproportionate number of cases of removal of the uterine appendages not affected by large cystic disease, as compared with those in which this large cystic disease had occurred, as if the two classes of cases had a constant relation to one another. Such an assumption is perfectly preposterous. The Middlesex Hospital has had for averylong time a number of beds devoted to cancerous diseases, and therefore cancerous cases have been attracted to that institution for very many years. It is more thanlikely, therefore, that the clientele of the Middlesex Hospital will have a larger proportion of cases of malignant disease in it than will have the London Hospital, where there is no such special provision, and where the population is, on the other hand, subject to a disproportionate number of accidents. Any institution which had existed for nearly a generation, such as the Samaritan Hospital, with a large reputation for dealing with ovarian tumours, will have a disproportionate number of tumour cases, and so on indefinitely. A number of qualifying incidents can be exposed which would render a constant relation of any two classes of cases in any one experience, either hospital or individual, equally improbable. Such relation must depend largely upon reputation and upon other surrounding circumstances, many of which are quite inscrutable.

Birmingham, Feb. 25th, 1891.

$$
\text { I am, Sirs, yours truly, }
$$
LAWSON TAIT.

\section{THE FACTORY ACT AND CERTIFYING SURGEONS.}

To the Editors of THE LANCET.

SIRs,-Kindly permit me briefly to supplement my letter of last week. The position of certifying factory surgeons was admirably defended by Sir Lyon Playfair, Sir F. Milner, and by many other members who followed, in the late debate in the House of Commons, and our thanks are due to them for their advocacy of our cause. But none of the speakers insisted sufficiently on one important point. It was argued that there was no reason for the existence of certifying surgeons, because there was little or nothing for them to do and their occupation was gone. It was stated that unhealthy "young persons" seldom or never presented themselves for examination or employment. This statement was by no means conclusively proved; but if true, why do the unfit decline to offer themselves? That is a crucial point, and one to which I wish to draw especial attention: plainly and clearly because employers and employed knew and know that it would be useless to do so in face of a law which requires a certificate not only of age but of health and fitness from a medical man. Abolish that deterrent influence, and as surely as night follows day you will behold a recurrence of the evils which that influence overcame and which it keeps so efficiently in check.

March 3rd, 1891. I am, Sirs, yours faithfully,

\section{NOTIFICATION OF INFECTIOUS DISEASES.}

\section{To the Editors of THE LANCET.}

Srns, - Would you allow me to endegvour to elicit through your columns the opinion of the profession on the following: The general adoption of the Notification of Infectious 